\section{Adjustable topical compression foot wrap, is more effective than a dopamine agonist, ropinirole, in reducing the symptoms of moderate to severe restless leg syndrome}

\author{
Dean Bender, ${ }^{1}$ Phyllis J. Kuhn, ${ }^{1}$ \\ Daniel J. Olson, ${ }^{2}$ John P. Sullivan ${ }^{3}$
}

'Lake Erie Research Institute, Inc., Girard, PA; ${ }^{2}$ BayCity Associates in Podiatry, Inc., Erie, PA; ${ }^{3}$ Neurology Associates of Erie, Erie, PA, USA

The objective was to measure the reduction of symptoms with an adjustable topical compression device (RESTIFFIC ${ }^{\mathrm{TM}}$ Brand Pressure Application System; Lake Erie Research Institute, Inc., Girard, PA, USA) of the foot in patients suffering with moderate to severe Willis-Ekbom disease [restless leg syndrome (RLS)].

We designed an experimental study: a single arm, open label single center clinical trial with a repeated measures design conducted from April 2009 to August 2012. Follow-up averaged 1.3 years.
Forty-seven patients were enrolled, 11 were excluded, 7 withdrew, one with usable results. 30 otherwise healthy adults, 22 women and 8 men, mean age 51.5 years, (range 30 to 75 years) diagnosed with moderate to severe primary RLS met eligibility criteria. Each patient was provided a pair of the RESTIFFIC ${ }^{\text {TM }}$ devices that applies targeted compression to the abductor hallucis and the flexor hallucis brevis muscles in the foot when worn during rest and sleep. Main measure, patient-generated International RLS study group (IRLSS) rating scale; secondary measure, physician-generated clinical global impression (CGI) scale. Patients were surveyed at period 1: baseline (no device) Day 1-7, 3 times per period; period 2: with device Days 8-28, 8 times per period; period 3: without device Days 29-35, 3 times per period; period 4: with device Days 36-56, 8 times per period. Meta-analysis used to compare RESTIFFIC ${ }^{\mathrm{TM}}$ to historic reports of ropinirole and placebo pill. Demographics, disease severity assessment tools are similar among studies.

RESTIFFIC $^{\mathrm{TM}}$ IRLSS score decreased from $25.05 \pm 5.33$ (a mean baseline on the Day 1) to $7.83 \pm 6.33$ (a mean score on Day 56 ), overall reduction of $17.22 \pm 6.16(\mathrm{P}=0.0001)$ representing two levels of improvement from severe to
Correspondence: Dean Bender, Lake Erie Research Institute, Inc., 8770 Brooks Road, Girard, PA 16417, USA.

E-mail: dbender@mediusa.com

This work is licensed under a Creative Commons Attribution 4.0 License (by-nc 4.0).

(C) Copyright D. Bender et al., 2016

Licensee PAGEPress, Italy

Veins and Lymphatics 2016; 5:5994

doi:10.4081/vl.2016.5994

mild. Change in mean IRLSS scores were significantly greater for RESTIFFIC ${ }^{\mathrm{TM}}, 17.22$, compared with historic reports of ropinirole, 12, and its placebo, $8.9(\mathrm{P}<0.05)$.

CGI responders were significantly increased for RESTIFFIC ${ }^{\mathrm{TM}}$, 90\% (27/30), compared with ropinirole 63\% (293/464) $(\mathrm{P}<0.05)$. Only minimal, transient side effects were reported that were relieved by loosening the straps.

RESTIFFIC $^{\mathrm{TM}}$ was 1.44 times as effective as historically reported ropinirole in reducing IRLSS scores. RESTIFFIC ${ }^{\text {TM }}$ represented a marked improvement over current pharmaceutical solutions in both efficacy and safety. 